\title{
Oil flow damage in Kraft paper 1: Thermal aging
}

\author{
Ian L. Hosier, \\ Tony Davies High Voltage \\ Laboratory, \\ University of Southampton, \\ Southampton, SO17 1BJ, UK \\ ilh@soton.ac.uk
}

\author{
Paul L. Lewin, \\ Tony Davies High Voltage \\ Laboratory, \\ University of Southampton, \\ Southampton, SO17 1BJ, UK \\ pll@ecs.soton.ac.uk
}

\author{
Gordon Wilson, \\ National Grid, \\ Warwick Technology Park, \\ Gallows Hill, \\ Warwick, CV34 6DA, UK \\ gordon.wilson@nationalgrid.com
}

\begin{abstract}
Thermal aging was used as a tool to prepare samples of Kraft paper spanning its entire life cycle in a high voltage transformer, from new to end of life. After characterization of DP and mechanical properties, selected samples were exposed to oil flows mimicking ONAN, OFAF and reclamation conditions. Aging combined with high flow rates, led to significant surface roughening but despite this, no significant erosion was detected even under reclamation conditions. Whilst the tests need to be repeated at higher oil temperatures which more closely reflect conditions in plant, these preliminary findings indicate that the paper insulation component is unlikely to be damaged by normal reclamation activities, even in significantly aged assets.
\end{abstract}

Keywords-Kraft paper, thermal aging, DP, mineral oil

\section{INTRODUCTION}

Kraft paper impregnated with mineral oil is used to form the insulation system of virtually all high voltage transformers. Whilst the oil primarily functions as both insulation and a coolant, it is the condition of the paper that ultimately determines asset life. Evidence obtained over a number of years by National Grid shows that mechanical failure of the paper is a leading cause of transformer failure [1]. As the paper ages, its degree of polymerisation (DP) and mechanical strength falls [2] until eventually, the paper is not able to withstand the electromechanical forces inherent to normal plant operation [3]. Deteriorated paper can compromise plant health in various ways; for instance, paper fragments can break away from the windings leading to short circuits or they can block oil ducts [2]. Furthermore, oil flow could exacerbate these effects; for instance, switching from natural cooling (ONAN) [4] to forced cooling (OFAF/ODAF) during periods of high electrical demand, leads to significantly increased oil flow rates [5]. A major concern is that routine reclamation employs very high oil flow rates $(>2000 \mathrm{l} / \mathrm{h})[6,7]$ which could cause erosion and further damage to the insulation system. Crucially, having an understanding of oil flow related erosion in Kraft paper will help network operators make better asset management decisions, particularly when reclaiming older units.

The current project seeks to understand the relationships between aging and mechanical damage when Kraft paper is exposed to oil flows mimicking those found in plant. In an earlier publication [8], the effects of thermal ageing on Kraft paper were presented - the DP was observed to fall and the paper became mechanically brittle. Thus, it is possible through laboratory aging, to provide paper samples in various conditions spanning the full life cycle of the transformer. In the second part of this ongoing work programme, which is discussed here, selected aged samples were characterised, impregnated with mineral oil and exposed to oil flow mimicking ONAN, OFAF and reclamation conditions. The resulting surface damage was assessed through optical microscopy, whilst measurements of sample thickness allowed any erosion to be quantified.

\section{METHODOLOGY}

\section{A. Paper aging and characterisation}

Transformer grade Kraft paper ( $0.1 \mathrm{~mm}$ thickness) was cut into $10 \times 10 \mathrm{~cm}$ pieces and hung on hooks in a fan oven to age at either 130 or $150{ }^{\circ} \mathrm{C}$. After this, the samples were left under ambient conditions $\left(25^{\circ} \mathrm{C}, \mathrm{RH}=45 \pm 10 \%\right)$ for at least $24 \mathrm{~h}$. Measurements of DP were then performed according to ASTM D4243 [2] by dissolving a small quantity of paper in a $0.5 \mathrm{M}$ solution of Bis(ethylenediamine) copper (II) hydroxide (Sigma Aldrich) and the viscosity was measured using a glass viscometer tube $(C=0.01)$ maintained at $20.0 \pm 0.5{ }^{\circ} \mathrm{C}$. Mechanical testing was performed on cut strips, nominally 70 x $15 \mathrm{~mm}$ in size, using a Tinius Olsen H25KS tensiometer (Gauge length: $50 \mathrm{~mm}$, crosshead speed: $10 \mathrm{~mm} / \mathrm{min}$ ).

\section{B. Oil flow testing}

Impregnation was carried out by placing the paper sheets in glass jars filled with new mineral oil (Nynas Gemini X) and drawing vacuum until all signs of visible bubbling had stopped (typically $1 \mathrm{~h}$ ). A bespoke oil flow tester was constructed using 1 " pipework and fittings according to the schematic shown in Fig. 1a. A tank (Flowfit, capacity 17 1) was fitted with two 400 W heaters and a pump (Jabsco, 40 size, max. flow rate $2100 \mathrm{l} / \mathrm{h}$ ) was connected to circulate the oil. A bypass valve (V) was installed to permit the oil flow to be varied, whilst a flow meter (Omega FLMH-1010AL-MA) was used to measure the flow rate. A bespoke Arduino based system was used to control the heaters and to log the oil temperature and flow rate.

A time stepping laminar flow model was implemented in COMSOL to establish the optimum geometry of the sample holder. It was found that a plate (onto which the paper sample can be attached using a metal shim), fixed at a $20^{\circ}$ angle to the horizontal in the centre of the tank, provides the most uniform velocity profile (Fig. 1b) where the oil jet adopts a flattened cross-section (Fig. 1b, inset). The model could also be used to 

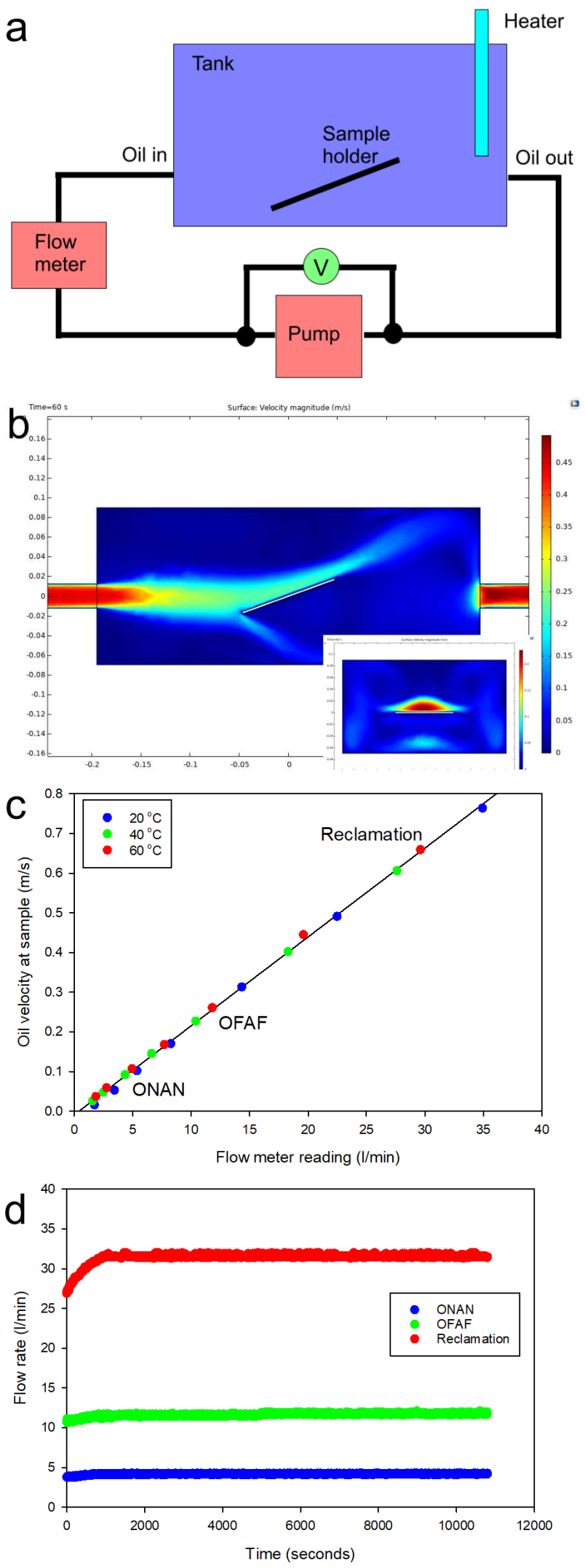

Fig. 1. Oil flow kit design (a) schematic, (b) typical results from COMSOL simulation (steady state, OFAF, $40^{\circ} \mathrm{C}$ ), (c) calibration graph for various oil teperatures from the simulation model (d) flow rates from warm up testing (room temperature to $40^{\circ} \mathrm{C}$ ) establish the relationship between the oil velocity at the sample and the flow rate at the inlet pipe (Fig. 1c). A review of the literature indicates that oil velocities of $0.05 \mathrm{~m} / \mathrm{s}(3-4 \mathrm{l} / \mathrm{min})$ and $0.25 \mathrm{~m} / \mathrm{s}(\sim 12 \mathrm{l} / \mathrm{min})$ are appropriate for ONAN and OFAF $[4,5]$ whilst the maximum available flow rate $(\sim 331 / \mathrm{min})$ was used to simulate reclamation $[6,7]$. Results from warm up tests under these three flow conditions (Fig. 1d) show that it is essential to heat the oil (here to $40{ }^{\circ} \mathrm{C}$ ) to achieve the highest flow rates. Consequentially, all flow tests were undertaken at $40{ }^{\circ} \mathrm{C}$ in new mineral oil for a duration of $6 \mathrm{~h}$ to fit within the working day, allowing some time for warm up ( $>30 \mathrm{~min})$.

\section{Characterisation of flow related damage}

Following flow testing, samples were extracted, submerged in a bath of acetone for at least $1 \mathrm{~h}$ and then left on absorbent material to dry. Optical microscopy was then performed under oblique illumination using a 4 MP USB microscope and finally ten independent measurements of the sample thickness were made. The thickness data were input into Microsoft Excel to yield an average value and a standard deviation. Finally, statistical tests (t-test) were undertaken between the various data sets to determine if any significant erosion had taken place.

\section{RESULTS}

\section{A. Initial characterisation of aged samples}

Fig. 2a summarises the change in DP as a function of aging time for both aging temperatures, each point being an average from three independent measurements. The DP falls nonlinearly with aging time and as expected, the aging rate is significantly slowed at the lower temperature of $130^{\circ} \mathrm{C}$. The
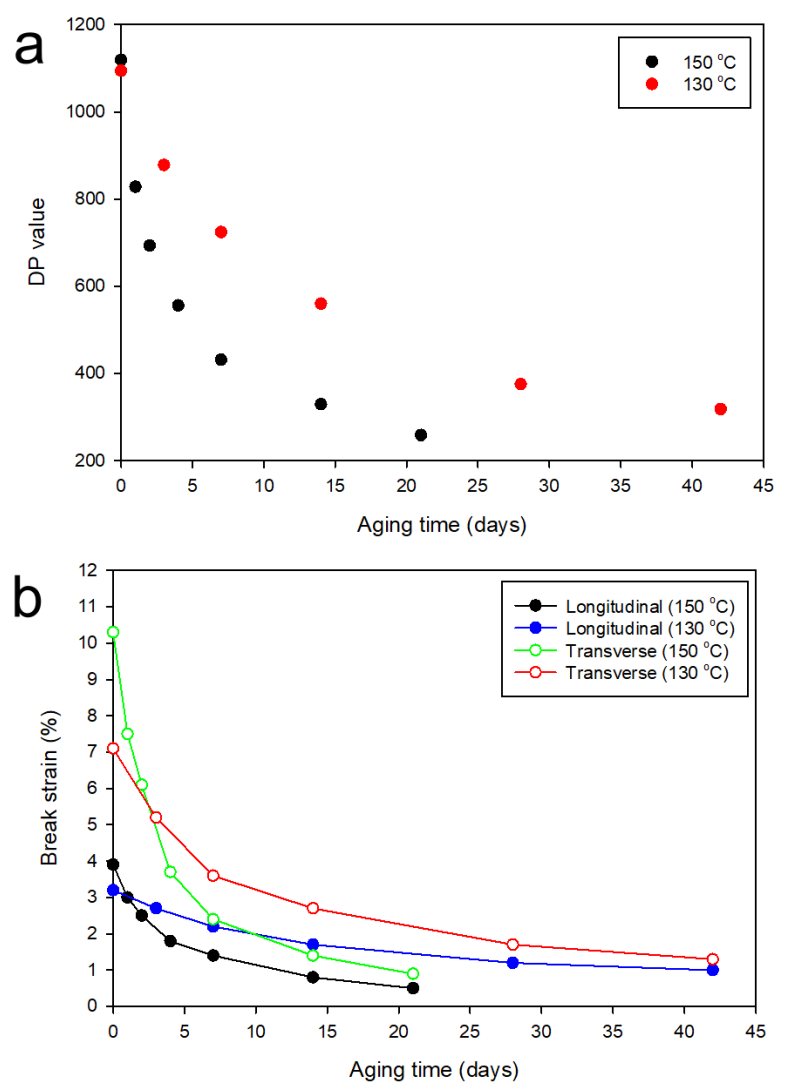

Fig. 2. Initial characterisation of aged samples (a) DP, (b) break strain 
full range of DP values from new $(\sim 1100)$ to end of life $(\sim 200)$ can be conveniently accessed through aging at $150^{\circ} \mathrm{C}$.

The break strain was determined from tensile tests and the average values obtained from three independent samples are summarised in Fig. 2b. An identical trend is evident for both aging temperatures and the data confirm that new paper is stiffer in the longitudinal or fibre direction (closed symbols) than in the transverse direction (open symbols) as expected [2]. As the paper is aged it becomes progressively more brittle, as exemplified by a decrease in break strain, until eventually the samples can be easily broken apart by hand.

New paper along with paper aged at $150{ }^{\circ} \mathrm{C}$ for 4,14 and 21 $\mathrm{d}$ were selected for flow testing, which provides a good spread of DP values (Fig. 2a) and mechanical properties (Fig. 2b).

\section{B. Observed surface damage due to oil flow}

Three distinctive surface morphologies could be identified following the oil flow tests. These were used to create a colour coded ranking table for the four aging conditions, two orientations and three flow rates (Table 1). Longitudinal orientation refers to oil flow along the fibre direction but throughout this investigation, the direction of oil flow (either in this direction or transverse to the fibre direction) did not affect the ranking scheme or the observed surface textures. Therefore, for the sake of brevity, only a small selection of representative images are shown in Fig. 3.

New and aged papers prior to any flow tests, and all samples subjected to ONAN conditions show the texture of Fig. 3a. Distinctive furrows (arising from the rolling process) are evident which are oriented along the fibre direction (from top left to bottom right). This indicates that no significant surface damage has occurred - blue ranking. Meanwhile, all samples exposed to oil flows mimicking OFAF conditions and less aged samples exposed to reclamation conditions, showed the "worn" appearance of Figs. $3 \mathrm{~b}$ and $3 \mathrm{c}$. Here noticeable erosion of the surface is evident as the furrows are now less obvious - green ranking. Finally, severely aged samples exposed to reclamation conditions are "rough looking" and have more disorganised textures with no evidence of furrowing as shown in Fig. 3d - red ranking. Here the surface layer (lignin) has been completely eroded by the oil flow leaving the underlying fibres exposed.

TABLE I. $\quad$ RANKING OF SAMPLES FROM OIL FLOW TESTING AT $40^{\circ} \mathrm{C}$

\begin{tabular}{|c|c|c|c|c|}
\hline \multirow{2}{*}{$\begin{array}{c}\text { Aging } \\
\text { time }\end{array}$} & \multirow{2}{*}{ Orientation } & \multicolumn{3}{|c|}{ Oil flow rate } \\
\hline & & $O N A N$ & $O F A F$ & Reclamation \\
\hline \multirow{2}{*}{ New } & Longitudinal & & & Fig. 3c \\
\hline & Transverse & Fig. 3a & & \\
\hline \multirow{2}{*}{$4 \mathrm{~d}$} & Longitudinal & & Fig. $3 b$ & \\
\hline & Transverse & & & \\
\hline \multirow{2}{*}{$14 \mathrm{~d}$} & Longitudinal & & & \\
\hline & Transverse & & & \\
\hline \multirow{2}{*}{$21 \mathrm{~d}$} & Longitudinal & & & \\
\hline & Transverse & & & Fig. 3d \\
\hline
\end{tabular}
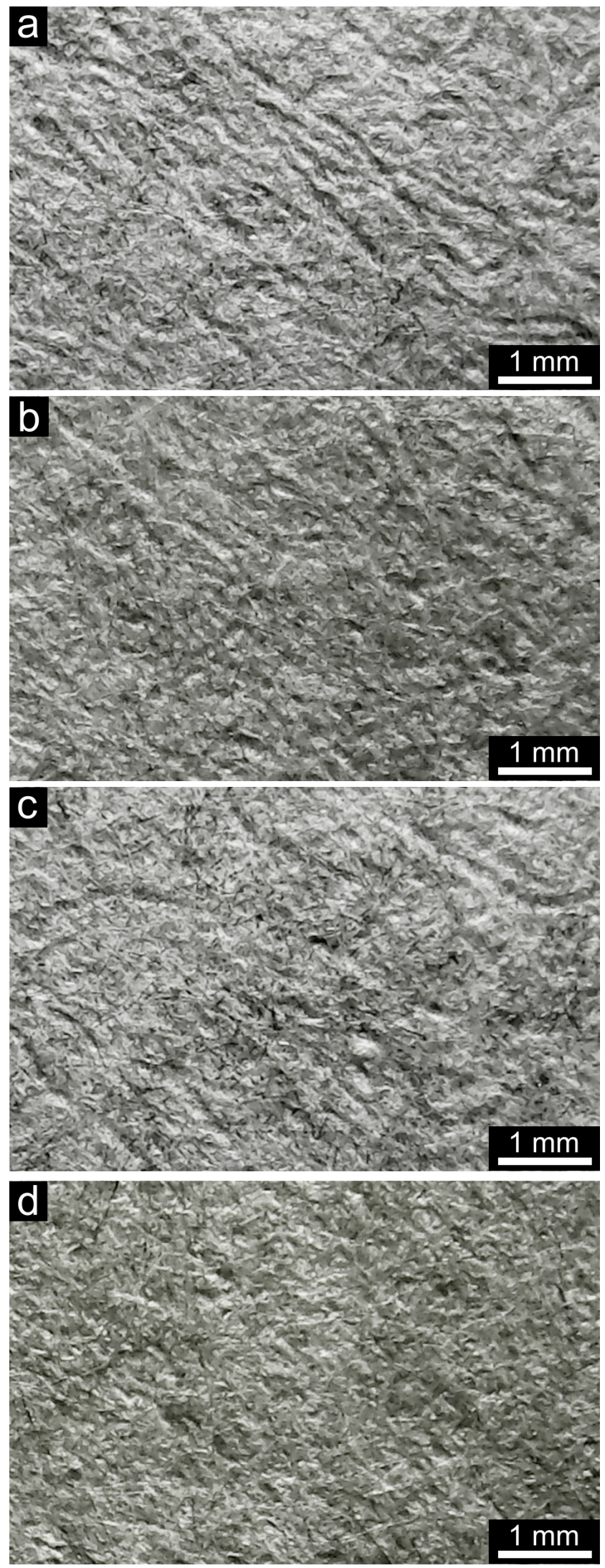

Fig. 3. Optical microscopy (a) new paper, ONAN conditions, (b) $4 \mathrm{~d}$ aged paper, OFAF conditions, (c) new paper, reclamation conditions, (d) $21 \mathrm{~d}$ aged paper, reclamation conditions 


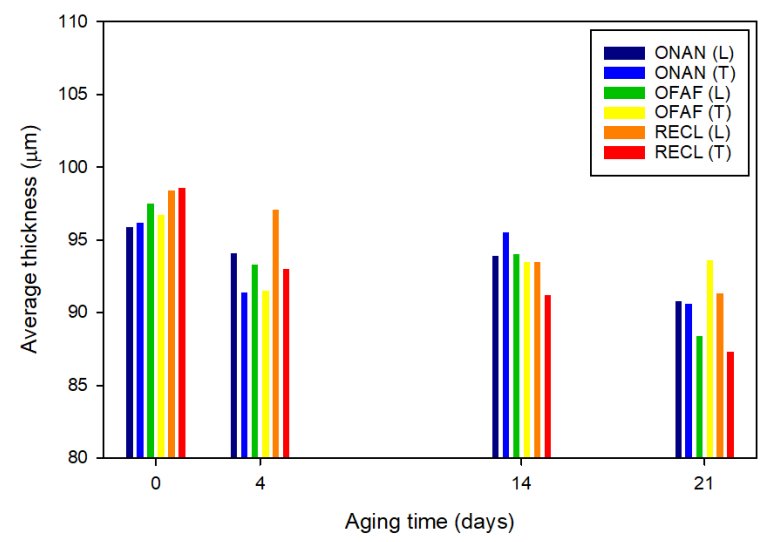

Fig. 4. Average thickness values as a function of flow conditions, orientation and aging time

It is clear from the above comparison that high rates of oil flow can lead to noticeable changes to the surface morphology of aged Kraft paper.

\section{Measurements of sample thickness}

Fig. 4 shows a histogram of average thickness values for the four aging times considered (new, $4 \mathrm{~d}, 14 \mathrm{~d}$ and $21 \mathrm{~d}$ ), three flow rates (ONAN, OFAF and reclamation) and two orientations (L or T). The standard deviation on these measurements is typically $6 \mu \mathrm{m}$; paper is a natural product and hence significant point to point variations in thickness were anticipated even in new paper.

Thermal aging has a small effect and reduces the average thickness of the paper from $97 \mu \mathrm{m}$ to $91 \mu \mathrm{m}$. However, a statistical comparison within each data group (any fixed aging time) did not reveal any significant effect of flow rate or sample orientation. This shows that there is no statistically significant flow related erosion (at least no erosion $>5 \mu \mathrm{m}$ which represents around $5 \%$ of the thickness of the paper) occurring in any of the samples considered in this investigation. Therefore, the morphological changes discussed in the previous section are confined solely to the surface layer of the paper $(<2 \mu \mathrm{m}$ or so).

\section{CONCLUSIONS}

Thermal aging was used as a tool to prepare aged paper samples spanning its entire life cycle within a high voltage transformer, from new to end of life. Aging causes the DP to fall and the paper becomes progressively more brittle.

A bespoke piece of equipment was constructed with the aid of a computer simulation model, and this equipment was then used to expose selected paper samples to oil flow rates mimicking ONAN, OFAF and reclamation conditions. It was found that the surface layer of aged paper can be noticeably disrupted by high oil flow rates. Despite this, a careful statistical analysis of measured thicknesses did not reveal any significant flow related erosion.

Whilst the flow tests need to be repeated at higher oil temperatures for longer times, which would more accurately mimic the thermal and flow cycling associated with a practical reclamation operation [6], the current findings indicate that the paper insulation component is unlikely to be damaged by normal reclamation activities, even in significantly aged assets.

\section{ACKNOWLEDGMENT}

The authors would like to acknowledge National Grid Electricity Transmission for supporting the project and agreeing to the publication of the results. The "TOPICS2" project (part of NIA_NGET0214) was made possible through the Network Innovation Allowance.

\section{REFERENCES}

[1] A. M. Emsley, R. J. Heywood, M. Ali, and X. Xiao, "Degradation of cellulosic insulation in power transformers. Part 4: Effects of ageing on the tensile strength of paper," IEEE Proc. Sci. Meas. Tech., vol. 147, pp. 285-290, 2000

[2] R. J. Heywood, A. M. Emsley, M. Ali, "Degradation of cellulose insulation in power transformers. Part 1: Factors affecting the measurement of the average viscometric degree of polymerisation of new and aged electrical papers", IEEE Proc. Meas. Technol., vol. 147, pp. 86 - 90, 2000.

[3] B. Yang, S. H. Wang, Y. P. HuangFu, G. L. Wang, H. J. Zhang, "Dynamic Deformation Analysis of Power Transformer Windings by Considering the Effect of Elasticity Characteristics of Kraft Paper", In Proc. 2013 IEEE Intern. Conf. Appl. Supercon. Electromag. Dev., pp. 395 - 398, 2013

[4] J. Gastelurrutia, J. C. Ramos, G. S. Larraona, A. Rivas, J. Izagirre, L. del Rio, "Numerical modelling of natural convection of oil inside distribution transformers", Appl. Therm. Eng., vol. 31, pp. 493-505, 2011.

[5] H. Campelo, C. M. Fonte, R.G. Sousa, J. C. B. Lopes, R. Lopes, J. Ramos, D. Couto, M. M. Dias, "Detailed CFD analysis of ODAF power transformers", In Proc. Intern. Coll. Transf. Res. Asset. Manag. (2009), DOI: $10.13140 / 2.1 .2854 .2402$

[6] R. P. Venkatasubramanian, "Experimental Assessment of Oil Regeneration Technique for Transformer Life Extension", PhD Thesis, University of Manchester, 2015, p. 67.

[7] J. S. N'Cho, I. Fofana, A. Beroual, T. Aka-Ngnui, J. Sabau, "Aged Oils Reclamation: Facts and Arguments Based on Laboratory Studies", IEEE Trans. Diel. Electr. Insul., vol. 19, pp. 1583-1592, 2012.

[8] I. L. Hosier, P. L. Lewin, J. Pilgrim, G. Wilson, "Effects of aging on the mechanical and dielectric properties of transformer grade kraft paper", In Proc. 2020 Electr. Insul. Conf., Art. no. 2141, 4 pp. (Knoxville, USA, 24th June - 2nd July 2020). 